\title{
APPLYING AN INDIGENOUS METHODOLOGY TO A NORTH-SOUTH, CROSS-CULTURAL COLLABORATION: SUCCESSES AND REMAINING \\ CHALLENGES
}

\begin{abstract}
This paper represents our collective reflexivity in the process of applying an Indigenous methodology in a North-South, cross-cultural collaboration, funded through Anonymous. The projects' aim was to bring together Bribri and Jakun leaders (from Costa Rica and Malaysia) for constructive dialogues about sustainable development. Specifically, we applied ulàpeitök, a concept of collaboration that honours family and community; we also used S-kốpàkö the Bribri word for conversation, a concept that translates to feeling the space around each other together. We analyze successes and challenges and elaborate on lessons learned including: 1) how and why Indigenous collaboration and reciprocity should be understood before a project is planned or financed, 2) why western academic concepts of reciprocity (such as one-to-one exchanges) need to be decolonized to include Indigenous ways of being and relating to others, and 3) paying special attention to language in the co-writing of publications to avoid cultural misrepresentation. Our research can inform other North/South, Indigenous/non-Indigenous collaborations that aim to contribute to decolonizing research.
\end{abstract}

Key words: Decolonizing Methodologies, Indigenous Research, Costa Rica, Malaysia

\section{Introduction}


The field of critical research is well-established across multiple disciples and is rooted in social justice principles (Denzin, 2015). Specifically, critical research has made important contributions to 1) interrogating power differences in research, 2) using research to reveal sites for change and activism, 3) foregrounding the voices of the oppressed, and 4) creating changes in our understanding of diversity, thereby broadening discourses (Koro-Ljungberg \& Cannella, 2017). Within the field of critical research, Indigenous methodologies are increasingly gaining attention in academic institutions.

Linda Tuhiwai Smith (2012) describes how research has been historically linked to Western imperialism and colonialism. Historically research has been conducted by and for white people of European descent on Indigenous research subjects. As a result, in academic settings Indigenous people’s stories have been told by outsiders and this has led to misrepresentation and denial of people’s rights to self-determination. Based on this history, Tuhiwai Smith (2012) defines research as one of the dirtiest words in Indigenous vocabulary. In response to injustices carried out in the name of research, Indigenous scholars have demonstrated how Indigenous values can guide research to transform a dark academic history. Some of these values include: 1) an epistemological position that differs from Western thought and ways of knowing, 2) accountability to family, clans, places, and non-human beings or nature 3) knowledge emerging from relationships with the land as well as from non-human beings, among others (for example Battiste, 2013; Brant Castellano \& Reading, 2010; Cajete, 2000; Hart 2010, Kovach, 2009; Tuhiwai Smith, 2012; Wilson 2008). When Indigenous values guide research, the impacts can include: 1) accurately representing people and their culture (Anonymous, 2017), 2) individual 
and community healing (Marsh, Cote-Meek, Toulouse, Najavits, \& Young, 2015) and 3) the survival of identities (Brant Castellano, 2004).

The majority of case studies that examine Indigenous values and ethics in research come from scholars working in the Global North in countries such as Australia, Canada, New Zealand, and the United States of America (for example, Battiste, 2013; Brant Castellano \& Reading 2010, Hart, 2010; Hernandez Castillo, Hutchings, \& Noble 2019; Kovach, 2009; Simonds \& Christopher, 2013; Tuhiwai Smith, 2012; Wilson, 2008). There is however, a growing theoretical and conceptual discussion about Indigenous knowledges and how this relates to methodologies in the Global South. Specifically, in reference to African perspectives, there has been a deep consideration of how hidden Western discourses may influence and skew research (Hoppers, 2002; Reviere, 2001). Mukherji (2004) argues for the need to debate the assumed universal application of Westernised social science methodologies in the South Asian context. In Latin America, there is a growing dialogue about decolonizing academia by both Indigenous and nonIndigenous scholars (Canales Tapia, 2014; Cumes, 2012; Nahuelpán Moreno 2014; Rivera Cusicanqui, 2012; Rocha-Buelvas \& Ruíz-Lurduy, 2018; Tzul Tzul 2015). Despite a rich academic dialogue, fewer studies examine how Indigenous methodologies are applied in the Global South (but see Anonymous, 2017; Datta, 2018; Figueroa Romero \& Burguete Cal y Mayor, 2017; Leyva Solano, 2019). 
Our goal is to expand our knowledge of how to apply Indigenous methodologies in the Global South. More specifically, our work fills an important gap, that is, to better understand better how cross-cultural teams working across North-South collaborations can apply Indigenous values to their research. Fisher, Shang, and Xie (2016) examined how to apply principles of critical research in a North-South partnership, however, these scholars did not work with Indigenous methodologies as we did in the present study. Understanding the application Indigenous values in North-South partnerships is important because many research and development projects in the Global North are designed to support Indigenous development in the Global South. The underlying political rationale behind such development projects requires illumination as these development projects can exert significant pressure to produce outcomes that are tailored to the needs of sponsoring Western countries and their private and/or government sectors. Even in cases where project goals may be compatible with some development goals in the south, funding limitations and deadlines can promote research that does not dedicate the time or resources needed to do ethical research (Berg \& Seeber, 2016). This fast, product-oriented, extractive research can affect the quality of scholarship (Berg \& Seeber, 2016) as well as reinforce the dominance of Western values and the exclusion of Indigenous ones (Kovach, 2009; RochaBuelvas \& Ruíz-Lurduy, 2018; Tuhiwai Smith, 2012).

With the aim of circumventing the negative impacts of outsider imposed, fast-pace research in a North-South, cross-cultural research collaboration with Indigenous communities, we applied an Indigenous research methodology to the first stages of our work. Specifically, our research took place in Costa Rica and was funded by Anonymous. Our topic was to better understand how the 
United Nations Sustainable Development Goals are relevant to Indigenous peoples’ daily lives and realities. The project's main aim was to bring together Indigenous leaders from Malaysia and Costa Rica to create constructive dialogues, where grievances as well as solutions would be explored and presented as recommendations to inform national policy change (Anonymous, 2019). The first phase of our work was in the Talamanca Bribri Territory where we were guests exploring building research relationships and exploring the research questions. Because the first phase of this project was held in the Bribri Talamanca Territory (Figure 1), we chose to use a Bribri Indigenous approach to research. Applying a Bribri approach was possible because Anonymous (author) has worked on this methodology for decades with his elders (for example Anonymous 1994, 2016; Anonymous, 1997). When we engage in phase two of this project, we will be guests of the Jakun people residing in the (Anonymous) community in Pahang, Malaysia; there we will learn and apply Jakun knowledge sharing approaches. This research was approved by the Anonymous community traditional authority (the community Elders) who Anonymous (author) consulted with before any community visits for this project took place. Secondly, this research was approved by the (Anonymous University) Ethics Committee.

The aims of this paper are to 1) describe how we applied Bribri values to this project's methodology and 2) highlight our successes and challenges in the process. We organize our paper as follows. First, we provide a background on the project, its collaborators and their institutions. Second, using the principle of reflexivity, we analyzed all stages of the research process, from building our collaboration to the publication of our results, in order to highlight lessons learned. Our findings will be relevant to researchers and practitioners working within 
Indigenous/non-Indigenous and/or North-South research teams who aim to minimize reinforcing power inequalities in their work.

\section{The Bribri Talamanca Territory and research collaboration details}

The research project is entitled "Being Developed? Comparing the experiences of economic and social development among Indigenous groups in Malaysia and Costa Rica”. The rationale for this project was to explore the perceived impact of the United Nations Sustainable Development Goals (SDG) on two nation states with Indigenous populations but with differing sustainable development agendas. The impacts of such agendas are experienced directly by Indigenous communities in terms of their right to ownership and access of traditional territories and the rights to practice traditional lifestyles. These rights are recognized in the UN Declaration on the Rights of Indigenous People (2007), to which both Malaysia and Costa Rica are signatories.

Costa Rica and Malaysia were chosen because the former provided a very useful comparison with the latter in terms of similarities and contrasts: developing nations, rich natural biodiverse, resources, an Indigenous minority population, clear socio-economic development agendas, as well as being signatories to the UN SDGs which refers to Indigenous people among other issues. A second strong consideration is that the researchers have long-term academic experience working in these countries. A third reason these countries were chosen is because our funding body would consider only those countries of low to middle income according to the World Bank country classification index. 
Our project was an interdisciplinary study to enable Indigenous leaders in Malaysia to exchange knowledge and experiences with Bribri Indigenous leaders in Costa Rica, and vice versa. Bringing Indigenous leaders together in both countries (Costa Rica in 2018 and repeated in Malaysia in 2019) has created a cycle of dialogues to better understand how SDGs can be made to work for the benefit of Indigenous peoples locally, leading to enhanced poverty reduction (SDG 1), conservation of traditional territories (SDG 15), better health and wellbeing (SDG 3), reduced social inequalities (SDG 10), and ensuring that habitats are more sustainable for all citizens (SDG 11). The specific goals of this project were to better understand Indigenous perspectives of development and the process was as important as the products; our study of development was not limited to asking Indigenous people what their perspectives on the SDGs or the national development agendas but also included community visits engaging in dialogue and practices using Indigenous approaches to sharing and conversing, practices that are examples of development. The products of this research include Jakun and Bribri definitions of development as expressed in practices as well as cultural knowledge and values. Indigenous scholars have expressed the need to better incorporate Indigenous perspectives with the 2030 development agenda (Cunningham Kain, 2018), and our goal was to contribute to this inter-cultural development perspective.

Our research team (authors of this paper) comprised of: 1) two UK researchers (Anonymous), 2) one Bribri researcher (Anonymous), 3) a Semelai researcher (Anonymous) and 4) a Canadian researcher (Anonymous). For this first phase of our work in Costa Rica, we worked in the 
Talamanca Bribri Territory. The Talamanca Bribri Indigenous territory is located in the Talamanca county and the Limón province in the southeastern region of Costa Rica. Bribri people have lived in the Talamanca region since time immemorial. In 2011, there were 7,772 Bribri people living in this territory (INEC, 2013). Specifically, we worked with (Anonymous author's) family and residents of the Anonymous community (Figure 1). The majority of (Anonymous community) residents work in export agriculture (banana, plantain, and cacao) and a few earn income as teachers and or labourers.

FIGURE 1: Map of the Talamanca region and the (Anonymous community) where this research was carried out (map created by Justin Geisheimer)

\section{Building a collaboration}

This research started when researchers from the UK contacted researchers from Costa Rica via email to invite them to collaborate in the project. The main project goals were developed by the UK researchers; however, in early conversations, (Anonymous authors), explained the need to do research based on Bribri methodologies to make space for Indigenous protocols, values, and ethics in academic research (see Anonymous, 2017). (Anonymous) been doing research based on Bribri values for over three decades and was selected by his elders to do so. Applying Indigenous values requires non-Indigenous researchers to practice critical self-reflection of the biases and power dynamics we bring to collaboration and to be open to sharing these reflections. In the rest of this paper we share our collective reflexivity regarding our research process. 


\section{Framing the collaboration based on Ulàpeitök, a Bribri way of working together}

Ulàpeitök is a traditional form of Bribri collaboration and translates to lend (peitök) a hand (ulà). Traditionally this concept is used when a family requires extra help with a task and often it is described in the context of working on the land. For example, if a person is growing corn using shifting cultivation (where plots are cultivated for periods and then left uncultivated for periods regeneration), a person can request ulàpeitök of their, relatives, clan members or friends. Requesting ulàpeitök implies that the person requesting assistance will provide people working with a meal and blo' (chicha, a fermented drink); this is not a direct payment of one meal for one person, however, it includes family members and children and people take home food to continue to share. If you have participated in ulàpeitök, you can then ask the person you worked for to work for you in the future and that person will help you directly or send one of their family or clan members. (Anonymous) explains that this Bribri form of reciprocity is different than the Western concept - where people directly exchange favours - because applying ulàpeitök implies working beyond the individual level and including families, members of your clan, as well as other community members; ulàpeitök is an Indigenous model of economy and of community development. Understanding how indigenous reciprocity is understood can reduce oversimplification of this process with Western notions, as McGregor and Marker (2018) explain, “...compensation or one-to-one, “fair” exchange (p. 3). This deep understanding is central to decolonial research because Western university cultural and administrative standards of reciprocity often differ greatly from Indigenous ones (McGregor \& Marker, 2018). 
Ulàpeitök shaped many aspects of our collaboration including how we negotiated the complexities of allocating Western audited research funding appropriately at the community level. (Anonymous) explains that direct monetary exchange for food and accommodation is not compatible with Bribri values nor with community development. Instead, following ulàpeitök, researchers are encouraged to provide an amount of money determined by a community collaborator (in our case (Anonymous) and his family and relatives) as a contribution to ulàpeitök. This money is used to prepare food during a research stay for everyone - not only the researchers - and can be used by family members of the community collaborator for other purposes. A pig is one example of something that can purchased with this money; pig meat is prepared as food for both researchers as well as host families and extra pig meat is then sold to other community members to provide extra income for families hosting researchers. Other ways a payment for ulàpeitök was used in our case was to compensate community members to harvest local and wild foods (for example, heart of palm and wild greens such as fiddlehead ferns). Money is thus, not directly exchanged for food and accommodation in a way that only one household would benefit, but rather used in a way that it provides food for researchers but also stimulates cultural practices such as traditional food harvesting as well as provides resources for multiple families and community members.

Applying ulàpeitök also meant that there was an abundance of traditional food being prepared in (Anonymous)'s family's homes while we were staying here and while we were doing research. This meant that when research participants were invited to come to his family members' homes to participate in conversation interviews, they were also offered a meal (as is traditional Bribri 
practice when you visit someone), and this meal included traditional and wild foods (for example, pig head stew, palm heart, or fiddlehead ferns). That research participants received a welcome with a traditional meal further reinforces Bribri values and culture in data gathering. (Anonymous) who has worked with this Bribri community for a decade now, explains that when she has done interviews on her own, approaching individual homes, she often resorts to bringing something she can buy in a corner store such as imported rice or packaged coffee; although this offering is appreciated it reinforces a conventional and non-Bribri way of doing research. But, when research is done within family homes, sharing traditional, local food prepared by host families, research participants are welcomed with a practice that illustrates respect and prioritization of Bribi ways of working together.

In western cultures, money is often exchanged for goods and services and it is not uncommon that, during research, outsiders pay a set fee for food and accommodation. (Anonymous) explains that this is not desirable if one is seeking to respect Bribri values; furthermore, paying for services defined by Western values (for example, food or accommodation) can further contribute to perpetuating research as a colonial intervention. Specifically, if a researcher pays only for their individual accommodation or meals then the emphasis in on the individual, whereas from a Bribri point of view the emphasis is on collaborating with social units, entire families and the community as a whole. Emphasis on the individual versus the community is a key contrast among Western and Indigenous research (Brant Castellano \& Reading, 2010; Cajete, 2000; Kovach, 2009; Little Bear, 2012; Wilson 2008). 
One example from our own research illustrates this point. In common with most competitive research funding, bids require evidence of cost effectiveness and due financial accountability from researchers. In this initial stage costs had been based roughly on previous ethnographic studies undertaken in developing nations by the UK researchers. However, in discussion with the Costa Rican-based colleagues it was explained that these were insufficient to cover the expectations of work in the Bribri community, based on these concepts of ulàpeitök. This was a serious consideration as the existing budget did not cover this eventuality where it had been assumed that subsistence and stay would be cheaper in the community than commercial rates in the city. There were also other expenses that had not been accounted for involved in staying with the community such as honoraria (as opposed to offering gifts in the original budget) that now needed to be accommodated.

Potentially offering a serious stumbling block to progress, it was extremely fortuitous that these expenses could ultimately be met from two different funding sources in the UK, where cultural expectations in respect of financial reciprocity made for a successful appeal. This, however, shows some key differences between a western and Indigenous perspective, where in developed nations there is a focus on research auditing based on economic per capita considerations, whereas an Indigenous view may focus on relational and community conventions. (Anonymous) explains this:

We need to see this[research] through Indigenous models or ways of life and ask ourselves how can we collaborate? We cannot measure this collaboration based only on economic 
terms... Ulàpeitök is a concept of community and social development. Every action that one does needs to be integral, it needs to be an action that benefits many people, my son, my daughter, my wife, my husband, my grandma, everyone in the house where you are staying.

As Margaret Kovach states (2009), colonial interruptions of Indigenous culture have occurred and continue to occur, and they have become part of Indigenous collective experiences. People, young and older, experience these colonial interruptions in day-to-day life, and they are part of the taken-for-granted normativity of Western research. Therefore, as researchers, we need to be aware of past and current colonial practices to highlight how actions, such as how we choose to plan for research room and board or how we share the benefits and costs of research, can reinforce the suppression of Indigenous values, perpetuate narratives of what is legitimate as research, and can exert the primacy of western approaches.

\section{Data gathering and knowledge sharing through conversation}

Conversation has been described as an Indigenous method that honours the oral nature of knowledge sharing (Kovach, 2010). The conversation method provides “...space, time, and an environment for participants to share their story in a manner that they can direct without the periodic disruptions involved in adhering to a structured approach, as in an interview format” (Kovach, 2009, p. 124). Beyond the ease that conversation as a data gathering method can afford research participants, (Anonymous) describes other reasons why conversation, S-kốpàkö, is culturally appropriate. Specifically, the meaning of S-kốpàkö comes from Se’ (us), Kố (place), Pà (everything that surrounds us) y Kö́k (touch). So what you are saying is let’s touch and feel, 
space, place, and the moment, together. If you ask someone to have a conversation, you are going to touch and feel the space around you together. (Anonymous) elaborates:

When I use the word S-kốpàkö, I am inviting you to share what we know, I am not asking only you to talk nor telling you what to talk about, I am saying that let's share a little about what we both know... Our language does not put any one person above the other, it says let's touch and feel our surroundings, it puts our knowledge at the same level and implies that we both have the possibility and capacity to perceive our surroundings. When someone refers to an interview or to asking questions, this does not reflect our reality because Indigenous people, Bribri, Cabécar and Nasö, do not ask questions. Asking questions, for us, is a way of measuring what the other person knows and therefore it is a form of aggression. Asking questions implies that you are looking to see if I know something; underlying this is the message that you think I do not know.

Due to the fact that the conversation method honours Bribri culture, we chose this method to gather and share knowledge. For (Anonymous), the benefits go beyond honouring Bribri practices and are also related to the quality of information that you obtain. In conventional interviews, interview guides are often predesigned, and interview sessions are scheduled at a set time. This, however, for (Anonymous) is not the way Bribri knowledge sharing occurs. This structured and scheduled format - focused on product versus process - can even elicit information that does not accurately represent Bribri people or their way of life or can result in short responses that do not convey the complexity of a situation. In such settings, many Bribri people in his community have historically, and continue to respond, (Anonymous) explains, either in a 
short concise way to questions and/or people provide answers that they believe outsider researchers want to hear. For these reasons, (Anonymous) describes why he does not use conventional interview methods; he conveys this message while referring to his own experiences interviewing a highly respected Elder and Awá (Bribri traditional doctor), Don Francisco García, when he was a youth:

I never work with people and say, ok, now tell me about a certain thing. Instead when they want to sit with me, we will talk...This was even the case with my paternal uncle, Don Francisco, who asked me to record his teachings, I didn’t ask him to tell me about a specific thing, I just listened. Remember that Bribri and Cabécar people feel things and when he [Don Francisco] felt the need to transmit something he would. You could ask him to tell you about something... but he would respond two words, and that was it. Then he would talk about something else, he would talk for an hour or half an hour talking about something else, extremely important as well, but he would share what he felt like sharing, not necessarily what you asked him.

This process of conversation as data gathering fits well with the non-Indigenous researchers' backgrounds in ethnographic research - a process of immersion into and alongside community members where slowness and relationship building are key, and where, in contemporary ethnographic practices, co-creation and co-construction of knowledge and understandings sit. Conversation also respects, as other Indigenous scholars have written, the view that there are 
stages of initiation to knowledge and that knowledge is contextual and requires the understanding of relationships, patterns, and cycles (Cajete, 2000).

\section{Slowing down and focusing on process}

Owing once again to budgetary restrictions fieldwork was at first visualized as reliant on intensive periods of data gathering by the academic team, but where professional facilitation by the Indigenous colleagues respectively would enable the community to work in a co-researcher paradigm. This latter plan took root once it was established that an intensive fieldwork trip was better curtailed to a short stay where introductions could be made and the research questions explored and considered by the community. Data was then gathered by (Anonymous) and his community for the first phase of the project.

As (Anonymous) explains, relationship building takes priority in order to avoid replicating fastpace, extractive, product-oriented work that can constitute the kind of output-driven, costorientated 'efficiencies’ that are valued in western contexts (Berg \& Seeber, 2016; McGregor \& Marker, 2018). (Anonymous) rejects the latter form of research because it does not adhere to the Bribri principle of building relationships nor does it produce accurate information about his culture and community members 
In reflecting on this process with his family members, (Anonymous) offers their view that in the end the visit to the community was too short. Bribri community members were still left curious about how the Jakun and Semelai people, guests in their community, live their lives.

(Anonymous) explains that Bribri people do not talk about things, but rather they do them. For this reason, Bribri community members also were left wanting to share more about their culture via actions such as forest walks, farming, harvesting, food preparation, and/or artisan activities. Participating in community activities, (Anonymous) explains, is more valuable than interviewing people about a particular topic, participation demonstrates you really want to know about his culture.

Modifying a research project to include more time and more community visits increased the economic needs of the research. This required renegotiating with budget holders in the UK to release more funds than had earlier been requested which then had been based on the assumption that fieldwork could be contained within one period of time. Eventually two sources of additional funding were tapped, an unusual and fortuitous circumstance, and these sources accepted our rationale of the time needed and resources needed to comply with Indigenous research protocol. That this projects' funding was increased is the exception rather than the rule and one reviewer of this paper importantly questioned what we would have done otherwise. The latter was an important point raised by (Anonymous), Bribri researcher, in our process. Specifically, he highlighted how a lack funding to do research in a way respectful of his community protocol would have jeopardized community relationships. Thus, to build respectful community relationships, we need to decolonize funding bodies and academic institutions, a 
process that can be supported by international guidelines. Specifically, the International Society for Ethnobiology's [ISE] (2006) Code of Ethics, articulates the need to raise awareness within funding bodies and academic institutions about the increased time and costs associated with Indigenous research that may be “...in addition to or even inconsistent with the policies of sponsoring institutions” (Practical guidelines: Considerations in collaborative, interdisciplinary, cross-cultural research section, para. 1).

\section{Research outcomes}

Margaret Kovach (2009) states "Indigenous methodologies require methods that give back to community members in a way that are useful to them. Giving back involves knowing what 'useful' means, and so having a relationship with the community, so that the community can identify what is relevant” (p. 81-82). McGregor and Marker (2018) outline important questions researchers need to ask themselves about reciprocity when working with Indigenous people including: 1) whose expectations are most important to fulfill, “...those of the research participants, the community to which they belong, the academic institution or research ethics board, or the researcher themselves” (p. 3) and 2) do university researchers ever offer people from communities something they really need?

Our project was designed so that the outcomes of our work could be identified by community members themselves and required researchers to have close relationships with the community. The UK researchers, with over 20 years researching in Malaysia, have developed good working relationships with the Malaysian (Anonymous) community over the past five years and 
maintained contact with individual members through such means as social media and contact with Indigenous activist networks. (Anonymous) is a member of the (Anonymous), Bribri community and (Anonymous) has worked with Bribri community members for 10 years. These relationships allowed us to determine the most useful and relevant outcomes for this project as it evolves. Below we describe the written outcomes of our work and some of the lessons learned in this process; however, despite the importance of compiling stories and publishing our research outcomes, the Indigenous exchanges and dialogues were of the most valuable outcomes; this includes exchanges during the research process as well as those that ensued once the official research trips were complete. Indigenous exchanges area a form of reciprocity via sharing knowledge (McGregor \& Marker, 2018), something leaders felt important to carry forward within their home communities and activism projects.

More specifically, bringing Indigenous leaders together was reported by Jakun and Bribri leaders to be extremely valuable to see and experience common strengths as well as challenges. Hernan García, Bribri Elder, explained how it was important to see how state-imposed policies of development regarding mining and industrial agriculture, without respect for Jakun rights, has led to areas of their territory that, as he observed and stated: were no longer alive. He explained how it is important to share this message with his community because similar development interventions could happen to them at any time in their territory; seeing Indigenous rights violations in Malaysia reinforced his view that Bribri people need to continue to strengthen their rights. Jakun Elder Ismail Muhamad, who travelled to Costa Rica, described how what he saw in the Bribri territory reminded himself of his community years back; specifically, he was moved 
by the strength of Bribri people's collective strength in the defensive of their land and culture as well as the health of the land and forests. After returning home, he said he was motivated to continue his work on strengthening Indigenous rights in Malaysia. Leaders from Malaysia and Costa Rica both expressed the importance of hearing inspiring messages from Elders in other cultural contexts; these messages, they described, helped them learn how they are not alone in their struggles and were important messages to share with community youth. Furthermore, one Bribri Elder, Hernan García, stated how he felt it was important to see how Indigenous people in Malaysia respect Elders just as Bribri people do; he wanted to convey this message to him community.

Owing to the importance of story-telling in Indigenous cultures one of the research outcomes proposed by Indigenous community members was the compilation of stories based on Bribri and Jakun perspectives on sustainable development as well as on other aspects of their lives and history (intellectual property and cultural rights regarding these stories is described below). Indigenous researchers have expressed how the use of story without an understanding of cultural epistemology can create problems in accurately representing Indigenous knowledge (Cajete, 2000; Datta, 2018; Kovach, 2009). (Anonymous) has decades of experience working with elders of his home community gathering stories and conveys the deep responsibility of ensuring cultural accuracy when oral story is transformed into written text.

Comment [A1]: Again, huge literature on this and it is not a new phenomenon. References are wellchosen but seem a bit limited here and in much of the paper. 
Our project illustrates how cultural accuracy is important not only in reporting Indigenous stories but also when outsider researchers are the primary authors of academic publications. One paper we wrote was reviewed by the Indigenous researchers on our team where some terms and concepts were discussed in order to avoid cultural misrepresentation that could potentially perpetuate power differences that reflect colonial relations. The word 'poverty' was identified as one that exemplifies very different attitudes among the research team, where it had at first been used to describe conditions in Indigenous communities - and is one of the challenges identified by the UN SDGs. After some discussion of language, the terms 'poverty' as well as 'village' were substituted in our publication in respect of the meanings of these terms for the Bribri community; (Anonymous) elaborates on this further:

When articles are published, at least in Costa Rica, people become easily influenced by them and attached to their messages. If you use the word village, people understand it as some abandoned area, a society that is backwards...something like Indiana Jones...poverty is another erroneous term. Indigenous people are not poor, the word does not even exist in the Bribri and Cabécar cultures. The word is an outside imposition and it is something created, from capitalism. It [poverty] is a way to dupe people so that they believe that Indigenous peoples are so poor, with nothing, and thus they can say anything they want or do anything they want to them; it is an indirect way to invalidate knowledge, wisdom, identity, local economy... poverty is used to say that because people are poor, I can simply do what I want with them. The fact that these Indigenous peoples do not have access or production of metal coins does not mean they are poor. They have a different development model, a local economy, one that is not based on dollars or colones or euros, but that is a way of life. 
Therefore, because in our project we are reclaiming Indigenous models, it seems contradictory to use terminology that illustrates to society that Indigenous people are... poor, living in a village and are a backwards... For this reason, I recommend eliminating these terms. They are subtle changes but at the same time very significant.

(Anonymous) clearly illustrates three key points when supporting Indigenous scholarship. First, the need to understand history and how Indigenous people have been described and treated by the dominant culture. Describing Indigenous people as poor in Costa Rica has been used as reason, as (Anonymous) explains, to do impose education, religion and healthcare practices that are not their own. Using this type of language can perpetuate erroneous stereotypes that have and continue to result in what (Anonymous) refers to as cultural genocide. Second, (Anonymous) illustrates the need to decolonize ourselves. Kovach (2009) describes this as “exploring one’s own beliefs and values about knowledge and how it shapes practices” (p. 169). Third, (Anonymous) illustrates the need to redefine roles in academic research. Scholars question the place of non-Indigenous people in Indigenous scholarship and highlight how non-Indigenous people need to support, not weaken, the work of Indigenous scholars (Leyva Solano, 2019, Noble, 2019; Pictou, 2019; Scott, 2019). Working on teams with Indigenous researchers means ensuring that these researchers are not only names on our publications but are active authors of their cultural realities. Despite that the poverty does not carry negative connotations in the UK context for our research team, and that it is a term commonly used within social policy, academic and media contexts (Alston, 2018; Townsend, 1979), our work illustrates why, in cross-cultural research, research articles must be reviewed by Indigenous colleagues to avoid perpetuating erroneous stereotypes. 
Authorship and intellectual property rights (IPRs) and cultural rights were also discussed in early stages of our collaboration. To respect Indigenous IPRs and cultural rights, it was agreed that stories would only be written up by Indigenous with guidance of their Elders. For example, (Anonymous) wrote up one Bribri story that for him describes a Bribri form of development with the support of his Elders, thus, this story does not have any single author but rather belongs to Bribri people and he is named as the cultural translator and interpreter and his Elders are named as those who told the story to him; these stories will be created into education materials for Indigenous and non-Indigenous audiences and will not be commercialized. Other outcomes of this project are peer-reviewed publications. We agreed that each researcher would take the lead on one article and thus will be its lead author; each member of the research team will also be a co-author on these publications.

\section{Institutional constraints associated with Indigenous research}

Academic and funding institutions also need decolonization as these will not always as amenable to some of the additional expenses associated with research with Indigenous communities as the UK funding streams proved to be in our specific case and project. As one reviewer of this paper importantly highlighted, academic and funding institutions are governed by colonial policies, laws, and mandates with legal accountabilities and this complex system is extremely complex and thus challenging to decolonize. Nonetheless, researchers can play an important role in this institutional decolonization process by including elements central to Indigenous research such as 
increased time in a community to account for trust building, honoraria for elders, cultural and language translators, dissemination in Indigenous languages, as well as other more context specific needs, such as ulàpeitök in our case. Ethnographic research has long reflected upon the need for meaningful relationship-building, co-production of knowledge, collaboration in data analysis and dissemination, and translation of results into multiple languages. However, we also need decolonization of institutional cultures (funding and academic institutions) so that researchers requests are honoured by funders and academic institutions. Commensurately, Berg and Seeber (2016) discuss how universities’ research goals are becoming increasingly aligned with corporate goals and values, which has created a push for research that is profitable, something that is compromising intellectual community and knowledge diversity. These authors call this the "supermarket model of research", a corporate model of research, based on speed, competition, and profit, one that threatens to exclude research that does not fit this model (Berg \& Seeber, 2016, p. 57).

\section{Power and Privilege}

Interrogating privilege is central to Indigenous research. One critique of two of our authors’ previous research was the disparity in opportunities for research; specifically, that nonIndigenous researchers often have the opportunity to travel to Indigenous communities to learn about their culture, but that the reverse is rarely the case (Anonymous, 2017). Our project was designed so that both Indigenous researchers and community members would travel abroad to learn from cultures different to their own, a key aspect of the project being dialogical encounters between Indigenous peoples for transformational change (Anonymous et al., 2019). 
Despite creating opportunities for Indigenous people to travel it may not be enough to include community members in travel plans without accounting for power and privilege. Three of our Indigenous participants had never travelled abroad thus necessitating new passports being obtained, as well as acquiring luggage and appropriate clothes. Furthermore, participating in the research demands financial sacrifice for some of our Indigenous participants, regardless that subsistence, accommodation and travel are covered by research funds. One participant, for instance, is a farmer who is not paid a salary but rather paid based on the food they produce. Leaving his home community to travel to Malaysia meant him losing over two weeks of work without any other income to fall back on. This was equally true of our Malaysian participants travelling to Costa Rica in phase one, and exemplifyes the commitment of the Indigenous participants to this study. However, to offset financial losses through payment for participation can create tensions in some contexts. In the UK context particularly, it can be considered questionable to pay research participants for involvement in research because this payment could potentially affect research findings. The latter is being actively addressed in Canada, where many universities have established honorarium payment guidelines for Indigenous people in the context of research and education (for example, Center for Indigenous Initiatives Carleton University, 2019; Indigenous Directions Leadership Group Concordia University, 2019; University of Alberta, 2019)

\section{Conclusion}


We all hold the responsibility and challenge to provide space for Indigenous methodologies and this is different than carrying out research in Indigenous communities. Kovach (2009) shares that "Indigenous research frameworks provide opportunities for tribal epistemologies to enter the tightly guarded academic research community” (p. 163). In the Global South, despite a strong literature on decolonization of academia, few studies have been published regarding the practical application of Indigenous methodologies in academic research; filling this gap is important because a lack of literature on how to apply Indigenous methodologies slows decolonization efforts in academia. Our research contributes to this gap and illustrates some of the successes and challenges of doing so in a North-South research collaboration working on a team of Indigenous and non-Indigenous researchers.

Our research specifically revealed three key findings. First, it was essential to have the important conversations early on in the project about how this research could be completed in a way that is mindful of colonial interruptions of Indigenous culture and we could avoid reinforcing negative impacts. More specifically, we illustrate the importance of understanding how Indigenous concepts of how collaboration and reciprocity are conceptualised before a project is planned or financed. Having the values for collaboration defined before funding is applied for will help ensure that there will be sufficient resources to account for elements of research that may not be common practice for outsiders to a community. Secondly, we found that western academic concepts of reciprocity (such as one-to-one exchanges) need to be decolonized to include Indigenous ways of being and relating to others; in our case, reciprocity in the form of ulàpeitök includes more than one-to-one exchanges and emphasizes the community over the individual. Third, our project revealed the importance of language in research dissemination; the use of the 
term poverty, in our case, was a key example. In the Bribri context, using poverty to describe Bribri people was described as reinforcing colonial-Indigenous relations used to perpetuate discrimination and inequality. In the UK context poverty was seen as factual language, analytically structural and in terms of empowerment, a socio-political tool to challenge disadvantage. The unpacking of meaning is increasingly possible when research is slowed down to devote time to examine cross-cultural nuances in the writing of research results. Overall, it is our hope that our lessons learned can inform other North/South, Indigenous/non-Indigenous research collaborations and contribute to the wider process of decolonizing academic research.

\section{Acknowledgements}

Removed for double-blind review

Declaration of conflicting interest

The author(s) declared no potential conflicts of interest with respect to the research, authorship, and/or publication of this article.

Funding

Removed for double-blind review

\section{Glossary}


Awá: Bribri traditional healer

Blo’: Chicha, a Bribri fermented drink made from corn, peach palm, or cassava

Bribri people: Indigenous people from the Talamanca Mountain Range, Costa Rica and traditionally hunter-gatherers. As of the 2011 census, there were 7,772 Bribri people living in the Talamanca Bribri Territory. Bribri people are matrilineal and Bribri is a Chibchan language.

Orang Asli: The Indigenous minority peoples of Peninsular Malaysia meaning original peoples in the Malay language.

Jakun people: The Jakun is the second largest Orang Asli group with a total population of 34,722, mainly settled in the states of Pahang and Johor. Jakun is an Austronesian language.

Semelai people: With a total population of 7,727 peoples, the Semelai are mainly located within Pahang and Negeri Sembilan states. Semelai is an Austroasiatic language.

S-kốpàkö: The Bribri word for conversation, a concept that translates to feeling the space around each other together

Ulàpeitök: Ulàpeitök is a traditional form of Bribri collaboration and translates to lend (peitök) a hand (ulà).

\section{References}

Alston, P. (2018, November 16). Statement on Visit to the United Kingdom. OHCHR. Retrieved from

https://www.ohchr.org/EN/NewsEvents/Pages/DisplayNews.aspx?NewsID=23881\&LangID=E

Anonymous et al. (2019). Details omitted for double-blind reviewing.

Anonymous (2018) Details omitted for double-blind reviewing.

Anonymous (2017). Details omitted for double-blind reviewing. 
Anonymous (2016). Details omitted for double-blind reviewing.

Anonymous (2013). Details omitted for double-blind reviewing.

Anonymous (1997). Details omitted for double-blind reviewing.

Anonymous (1994). Details omitted for double-blind reviewing.

Battiste, M. (2013). Decolonizing education: Nourishing the learning spirit. Vancouver: UBC Press.

Berg, M. \& Seeber, B. K. (2016). The slow professor: Challenging the culture of speed in the academy. Toronto: University of Toronto Press.

Brant Castellano, M. \& Reading, J. (2010). Policy writing as dialogue: Drafting an Aboriginal chapter for Canada’s Tri-Council Policy Statement: Ethical Conduct for Research Involving Humans. The International Indigenous Policy Journal, 1(2), DOI: 10.18584/iipj.2010.1.2.1

Brant Castellano, M. (2004). Ethics of Aboriginal research. Journal of Aboriginal Health. January, 98-114. 
Cajete, G. (2000). Native science: Natural laws of interdependence. Santa Fe: Clear Light Publishers.

Canales Tapia, P. (2014). Intelectualidad indígena en américa latina: debates de descolonializacion, 1980-

2010 [Indigenous knowledge in Latin America: Debates of decolonization 1980-2010]. Universum, 29(2),

49-64.

Center for Indigenous Initiatives Carleton University. (2019). Guidelines for working with

Elders. Retrieved from https://carleton.ca/indigenous/resources/guidelines-for-working-with-

$\underline{\text { elders/ }}$

Cumes, A. E. (2012). Mujeres Indígenas, patriarcado y colonialismo: Un desafía a la segregación comprensiva de las formas de dominio [Indigenous women, patriarchy, and colonialism: A challenge to the comprehensive segregation of types of domination]. Anuario Hojas de Warmi, $17,1-16$.

Cunningham Kain, M. (2018). Objetivos de desarollo sostenible y pueblos indigenas: La interculturalidad como requisite de paz y desarrollo. Tiempo de Paz, 131, 31-40.

Datta, R. (2018). Traditional storytelling: An effective Indigenous research methodology and its implications for environmental research. AlterNative, 14, 35-44.

Denzin, N. (2015). What is critical qualitative inquiry? In G. S. Cannella, M. S. Perez, \& P. A. Pasque (Eds.), Critical qualitative inquiry (pp. 31-50). Walnut Creek: Left Coast Press. 
Figueroa Romero, D. \& Burguete Cal y Mayor, A. (2017). Indigenizing social research methodologies: An analysis of the Diploma Program for Strengthening Indigenous Women’s Leadership. AlterNative: An International Journal of Indigenous Peoples, 13(4), 235-245.

Fisher, K. R., Shang, X., \& Xie, J. (2016). Global South-North partnerships: Intercultural methodologies in disability research. In S. Grech, K. Soldatic (Eds.), Disability in the Global South (pp. 567-582). Cham: Springer International Publishing AG.

Hart, M. A. (2010). Indigenous worldview, knowledge, and research: The development of an Indigenous research paradigm. Journal of Indigenous Voices in Social Work, 1(1), 1-16.

Hernandez Castillo, R. A., Hutchings, S. \& Noble, B. (Eds). (2019). Transcontinental dialogues: Activist alliances with Indigenous peoples of Canada, Mexico, and Australia. Tucson: The University of Arizona Press.

Hoppers, C. A. (2002). Indigenous knowledge and the integration of knowledge systems. New Africa Books. Cape Town. South Africa.

Indigenous Directions Leadership Group Concordia University. (2019). Indigenous Elder and community protocols. Retrieved from 
https://www.concordia.ca/content/dam/concordia/offices/oce/IDLG/Indigenous-Elder-and-

Community-Protocols.pdf

INEC (2013). X Censo nacional de población y VI de vivienda: Territorios Indígenas [ $5^{\text {th }}$ National population $\& 6^{\text {th }}$ housing census: Indigenous territories]. San Jose, Costa Rica: Instituto Nacional de Estadística y Censos.

International Society for Ethnobiology's [ISE] (2006). International Society of Ethnobiology Code of Ethics (with 2008 additions). Retrieved from http://www.ethnobiology.net/what-wedo/core-programs/ise-ethics-program/code-of-ethics/code-in-english/

Koro-Ljungberg, M. \& Cannella, G. S. (2017). Critical qualitative inquiry: Histories, methodologies, and possibilities. International Review of Qualitative Research, 10(4), 327-339.

Kovach, M. (2010). Conversational method in Indigenous research. First Peoples Child \& Family Review, 5(1), 40-48.

Kovach, M. (2009). Indigenous methodologies: Characteristics, conversations and contexts. Toronto, Canada: University of Toronto Press Incorporated. 
Little Bear, L. (2012). Traditional knowledge and humanities: A perspective by a Blackfoot. Journal of Chinese Philosophy, 39(4), 518-527.

Leyva Solano, X. (2019). Decolonizing anthropologists from below and to the left. In

R.A., Hernandez Castillo, S. Hutchings, \& B. Noble. (Eds.). Transcontinental dialogues: Activist alliances with Indigenous peoples of Canada, Mexico, and Australia. Tucson: The University of Arizona Press.

Marsh, T. N., Cote-Meek, S., Toulouse, P., Najavits, L. M., \& Young, N. L. (2015). The application of two-eyed seeing decolonizing methodology in qualitative and quantitative research for the treatment of intergenerational trauma and substance use disorders. International Journal of Qualitative Methods, 14, 1-13.

McGregor, H. E. \& Marker, M. (2018). Reciprocity in Indigenous Educational Research: Beyond Compensation, Towards Decolonizing. Anthropology \& Education Quarterly, 49(3), https://doi.org/10.1111/aeq.12249

Mukherji, P. N. (2004). Indigeneity and universality in social science. New Delhi: Sage.

Nahuelpán Moreno, H. J. (2013). El lugar del “indio” en la investigación social. Reflexiones en torno a un debate político y epistémico aún pendiente [The “Indian’s” place in social research. Reflections regarding a pending political and epistemological debate]. Revista Austral de Ciencias Sociales, 24, 71-91. 
Noble, B. (2019). Epilogue. Grounded allies: Acting-with, regenerating together. In R.A., Hernandez Castillo, S. Hutchings, \& B. Noble (Eds.). Transcontinental dialogues: Activist alliances with Indigenous peoples of Canada, Mexico, and Australia. Tucson: The University of Arizona Press.

Pictou, S. M. (2019). What is Decolonization? Mi'kmaw ancestral relational understandings and anthropological perspectives on treaty relations. In R.A., Hernandez Castillo, S. Hutchings, \& B. Noble (Eds.). Transcontinental dialogues: Activist alliances with Indigenous peoples of Canada, Mexico, and Australia. Tucson: The University of Arizona Press.

Reviere, R. (2001). Toward an Afrocentric research methodology. Journal of Black Studies, 31(6), 709-727.

Rivera Cusicanqui, S. (2012). Ch'ixinakax utxiwa: A reflection on the practices and discourses of decolonization. The South Atlantic Quarterly, 111(1), 95-109.

Rocha-Buelvas, A. \& Ruíz-Lurduy, R. (2018). Agendas de investigación indígena y decolonialidad [Agendas for indigenous research and decoloniality]. Izquierdas, 41, 184-197. 
Simonds, V.W. \& Christopher, S. (2013). Adapting Western research methods to Indigenous ways of knowing. American Journal of Public Health. 103, 12, 2185-2192.

Scott, C. (2019). Research partnerships and collaborative life projects. In R.A., Hernandez Castillo, S. Hutchings, \& B. Noble (Eds.). Transcontinental dialogues: Activist alliances with Indigenous peoples of Canada, Mexico, and Australia. Tucson: The University of Arizona Press.

Townsend, P. (1979) Poverty in the United Kingdom: A survey of household resources and standards of living. Harmondsworth: Penguin Books.

Tuhiwai Smith, L. (2012)[1999]. Decolonizing methodologies: Research and Indigenous peoples, $2^{\text {nd }}$ edition. London: Zed Books Ltd.

Tzul Tzul, G. (2015). Mujeres indígenas: Historias de la reproducción de la vida en Guatemala. Una reflexión a partir de la visita de Silvia Federici [Indigenous women: Stories of the production of life in Guatemala. A reflection from the visit of Silvia Federici]. Bajo el Volcán, 22, 91-99.

UN. (2007). United Nations Declaration on the Rights of Indigenous People. Retrieved from https://www.un.org/development/desa/indigenouspeoples/wpcontent/uploads/sites/19/2018/11/UNDRIP_E_web.pdf 
University of Alberta. (2019). First Nations, Métis and Inuit Honorarium Payment Guidelines.

Retrieved from https://www.ualberta.ca/human-resource-services/hrs-news/2019/march/first-

nations-metis-and-inuit-honorarium-payment-guidelines.html

Wilson, S. (2008). Research is ceremony: Indigenous research methods. Nova Scotia: Fernwood Publishing Co. Ltd. 